\title{
Cirsium japonicum var. Maackii Improves Cognitive Impairment under Amyloid Beta ${ }_{25-35}$-Induced Alzheimer's Disease Model
}

\author{
Qi Qi Pang, ${ }^{1}$ Ji-Hyun Kim, ${ }^{1}$ Ji Myung Choi, ${ }^{1}$ Jia-Le Song $\mathbb{D}^{2}{ }^{2}$ Sanghyun Lee, ${ }^{3}$ \\ and Eun Ju Cho ${ }^{1}$ \\ ${ }^{1}$ Department of Food Science and Nutrition, Institute of Kimchi Research, Pusan National University, \\ Busan 46241, Republic of Korea \\ ${ }^{2}$ Department of Nutrition and Food Hygiene, School of Public Health, Guilin Medical University, Guilin 541004, China \\ ${ }^{3}$ Department of Plant Science and Technology, Chung-Ang University, Anseong 17546, Republic of Korea
}

Correspondence should be addressed to Eun Ju Cho; ejcho@pusan.ac.kr

Received 12 April 2021; Revised 20 October 2021; Accepted 13 December 2021; Published 6 January 2022

Academic Editor: Nahide Gulsah Deniz

Copyright (C) 2022 Qi Qi Pang et al. This is an open access article distributed under the Creative Commons Attribution License, which permits unrestricted use, distribution, and reproduction in any medium, provided the original work is properly cited.

\begin{abstract}
Abnormal production and degradation of amyloid beta $(\mathrm{A} \beta)$ in the brain lead to oxidative stress and cognitive impairment in Alzheimer's disease (AD). Cirsium japonicum var. maackii (CJM) is widely used as an herbal medicine and has antibacterial and anti-inflammatory properties. This study focused on the protective effect of the ethyl acetate fraction from CJM (ECJM) on $\mathrm{A} \beta_{25-35}$-induced control mice. In the T-maze and novel object recognition test, ECJM provided higher spatial memory and object recognition compared to $\mathrm{A} \beta_{25-35}$ treatment alone. In the Morris water maze test, ECJM-administered mice showed greater learning and memory abilities than $\mathrm{A} \beta_{25-35}$-induced control mice. Additionally, ECJM-administered mice experienced inhibited lipid peroxidation and nitric oxide production in a dose-dependent manner. The present study indicates that ECJM improves cognitive impairment by inhibiting oxidative stress in $\mathrm{A} \beta_{25-35}$-induced mice. Therefore, CJM may be useful for the treatment of $\mathrm{AD}$ and may be a potential material for functional foods.
\end{abstract}

\section{Introduction}

Alzheimer's disease (AD) is a neurodegenerative disease, and its main feature is the excessive accumulation of amyloid beta $(\mathrm{A} \beta)$ peptides in the brain [1]. $\mathrm{A} \beta$ is derived from amyloid precursor protein (APP) through the proteolytic cleavage of a family of enzymes ( $\beta$ - and $\gamma$-secretase), which leads to memory loss and cognitive decline by the formation of senile plaques [2]. Previous studies have demonstrated that the accumulation and aggregation of $\mathrm{A} \beta$ (i.e., oligomers and senile plaques) are highly neurotoxic and form $\mathrm{A} \beta$ deposit/fibrils, which can contribute to $\mathrm{AD}$ development [3]. $\mathrm{A} \beta$ oligomers in the early stage and $\mathrm{A} \beta$ plaques in later stages are established, so they are observed in the AD brain for decades before the onset of memory/behavior/cognitive symptoms [4]. Therefore, therapeutic approaches targeting
$\mathrm{A} \beta$ by regulating the $\mathrm{A} \beta$ mechanism have attracted attention. The $\mathrm{A} \beta_{25-35}$ fragment used in the present study, a core toxic fragment cleaved from the full-length $\mathrm{A} \beta$ peptide, plays a critical role in the development of $\mathrm{AD}$ by inducing oxidative stress, neurotoxicity, and inflammatory response [5].

Oxidative stress is caused by the disequilibrium of the redox reaction and generates excessive reactive oxygen species (ROS) in the body [6]. The brain, which consumes large amounts of oxygen, may be notably sensitive to oxidative damage [7]. Moreover, several studies have reported that metal ions (e.g., zinc, iron, and copper) that bind $\mathrm{A} \beta$ exist in $\mathrm{A} \beta$ plaques and modulate the aggregation process. $\mathrm{A} \beta$ plaques with entrapped metal ions produce free radicals, such as ROS and reactive nitrogen species (RNS) [8]. Thus, the accumulation of $A \beta$ induces oxidative stress in the brain, resulting in lipid peroxidation, protein oxidation, and 
cognitive impairment [5, 9]. Moreover, many studies have reported that $\mathrm{A} \beta$ activates microglia, leading to the release of inflammatory cytokines, such as interleukin- $1 \alpha$, interleukin- $1 \beta$, and tumor necrosis factor- $\alpha$ [10]. Subsequently, pathologic changes in the microglia contribute to the secretion of proinflammatory materials, including ROS and RNS, which trigger detrimental inflammation. This inflammatory-oxidative stress cycle means that $\mathrm{A} \beta$ induces inflammatory signals, which then release ROS and RNS. This further evokes inflammation, and the entire process develops into an inflammatory-oxidative stress cycle [11, 12]. Therefore, $\mathrm{A} \beta_{25-35}$-induced in vivo mouse models have been used to investigate oxidative stress and cognitive impairment in $\mathrm{AD}$ patients.

Cirsium japonicum var. maackii (CJM) is a perennial herb of the chrysanthemum family and is mainly distributed in China, Korea, Japan, and other places [13]. Several pharmacological benefits of CJM have been reported that it has anti-inflammatory and antihypertensive effects [14, 15]. In addition, $\mathrm{Oh}$ et al. [16] demonstrated that the CJM flower exerted anticancer activity by inhibition the PI3K-Akt signaling pathway. In addition, the CJM indicated the remarkable protective activities from oxidative stress-related diseases including diabetes mellitus. Furthermore, Wagle et al. [17] demonstrated that isolated compound luteolin from CJM showed the anti-AD activity through the suppression of BACE1 ( $\beta$-secretase), which formed the amyloid beta by cleaving the amyloid $\beta$ precursor protein. Flavonoids such as cirsimarin, cirsimaritin, hispidulin, and pectolinarin are usually isolated from CJM, and these mediate the pharmacological properties of CJM [18]. Lee et al. [18] verified that the highest constituent from EtOAc fraction of CJM is cirsimaritin, following cirsimarin and hispidulin. In addition, apigenin and luteolin are major constituents in the EtOAc fraction of CJM flower [19]. In particular, we reported that pectolinarin from the EtOAC fraction of CJM has neuroprotective effects [20].

Many studies have demonstrated that the ethyl acetate (EtOAc) fraction of CJM (ECJM) significantly inhibited aldose reductase, $\alpha$-glucosidase, oxidative stress, and inflammation [14, 17, 18, 21, 22]. Moreover, in our previous study, among the four fractions of CJM, including EtOAc, dichloromethane $\left(\mathrm{CHCl}_{3}\right), n$-butanol $(\mathrm{BuOH})$, and $n$-hexane, the EtOAc fraction showed the strongest biological activity against $\mathrm{A} \beta_{25-35}$-induced cytotoxicity in SH-SY5Y neuronal cells [20]. This suggests that CJM may have a potential protective effect on $\mathrm{AD}$ and ECJM is the major active fraction with beneficial health effects. Accordingly, the EtOAc fraction of CJM was selected for further in vivo studies to investigate its protective effects against $\mathrm{A} \beta_{25-35}$-induced cognitive impairment. However, there have been no studies on the protective effects of ECJM against $A \beta_{25-35}$-induced cognitive impairment in an in vivo mouse model. Therefore, in the present study, we investigated the protective effects and mechanisms of ECJM on $\mathrm{A} \beta_{25-35}$-induced cognitive impairment in mice by exploring behavioral tests and measuring lipid peroxidation and nitric oxide (NO) production.

\section{Materials and Methods}

2.1. Plant Materials and Sample Preparation. The aerial part of CJM was obtained from Imsil Herbal Medicine (Imsil, Korea). Dried CJM $(5.7 \mathrm{~kg})$ was extracted with ethyl alcohol $(\mathrm{EtOH})$ for $3 \mathrm{~h}$ at $65-75^{\circ} \mathrm{C}$ under reflux, and $667.2 \mathrm{~g}$ of EtOH extract was obtained (yield 11.7\%). The EtOH extract was supplemented with water and partitioned with EtOAc, $\mathrm{CHCl}_{3}, n-\mathrm{BuOH}$, and $n$-hexane in the present study; only the $\mathrm{EtOH}$ fraction was used to investigate the improvement effects on $\mathrm{A} \beta_{25-35}$-induced cognitive impairment. The EtOAc fraction (67.6g) was obtained (yield 10.1\%) and dissolved in distilled water (DW) for use [18].

2.2. Reagents. $\mathrm{A} \beta_{25-35}$, donepezil, malondialdehyde (MDA), and Griess reagent were purchased from Sigma-Aldrich Co. (St. Louis, MO, USA). Phosphoric acid and butanol were obtained from Samchun Chemical Co., Ltd. (Seoul, Korea). Thiobarbituric acid (TBA) was obtained from Lancaster Synthesis (Ward Hill, MA, USA), and trichloroacetic acid (TCA) was acquired from Kanto Chemical Co., Inc. (Tokyo, Japan).

2.3. Animals and Experimental Designs. Male ICR mice (5 weeks old; Orient Inc., Gyeonggi-do, Korea), weighing 24$27 \mathrm{~g}$, were fed in transparent plastic cages and provided with diet and water for free use. The housing environment was maintained at a temperature of $20 \pm 2^{\circ} \mathrm{C}$, humidity of $50 \pm$ $10 \%$, and light and dark cycle movements were controlled for $12 \mathrm{~h}$. The mice were adapted for a 7-day period before $\mathrm{A} \beta_{25-35}$ administration, and a total of 35 mice were randomly divided into five groups ( $n=7$ per group) by similar average weight without significant body weight differences among groups. On the 8th day of the experiment, mice were administered $5 \mu \mathrm{L} \mathrm{A} \beta_{25-35}$ at a concentration of $5 \mathrm{nM} / \mu \mathrm{L}$. Between the 14th day and 27th day of the experiment, the ECJM50 group and ECJM100 group were orally administered $50 \mathrm{mg} / \mathrm{kg}$ ECJM and $100 \mathrm{mg} / \mathrm{kg}$ ECJM, respectively, once a day for 14 days. Each group was defined as follows: (1) sham group-injection of $0.9 \% \mathrm{NaCl}$ and oral administration of water; (2) control group-injection of $\mathrm{A} \beta_{25-35}$ and oral administration of water; (3) ECJM50 group-injection of $\mathrm{A} \beta_{25-35}$ and oral administration of ECJM $(50 \mathrm{mg} / \mathrm{kg} /$ day); (4) ECJM100 group-injection of $\mathrm{A} \beta_{25-35}$ and oral administration of ECJM (100 mg/kg/day); and (5) donepezil group-injection of $\mathrm{A} \beta_{25-35}$ and oral administration of donepezil ( $5 \mathrm{mg} / \mathrm{kg} /$ day). ECJM and donepezil were dissolved in DW before use. In our experiment, mice were orally administered ECJM or donepezil in a volume of $100 \mu \mathrm{L}$ for 14 days by gastric gavage. All of the studies were carried out according to the guidelines of the Pusan National University Institutional Animal (PNU-IACUC, approval number: PNU-2019-2393). The timeline of the experiments is shown in Figure 1.

2.4. Animal Model. A $\beta_{25-35}$ was dissolved in $0.9 \% \mathrm{NaCl}$ solution and incubated at $37^{\circ} \mathrm{C}$ for $72 \mathrm{~h}$ at a concentration of $5 \mathrm{nM} / \mu \mathrm{L}$ [23]. Before the intracerebroventricular (i.c.v.) injection, a mixture of tiletamine hydrochloride and zolazepam hydrochloride was prepared and mixed with xylazine at 


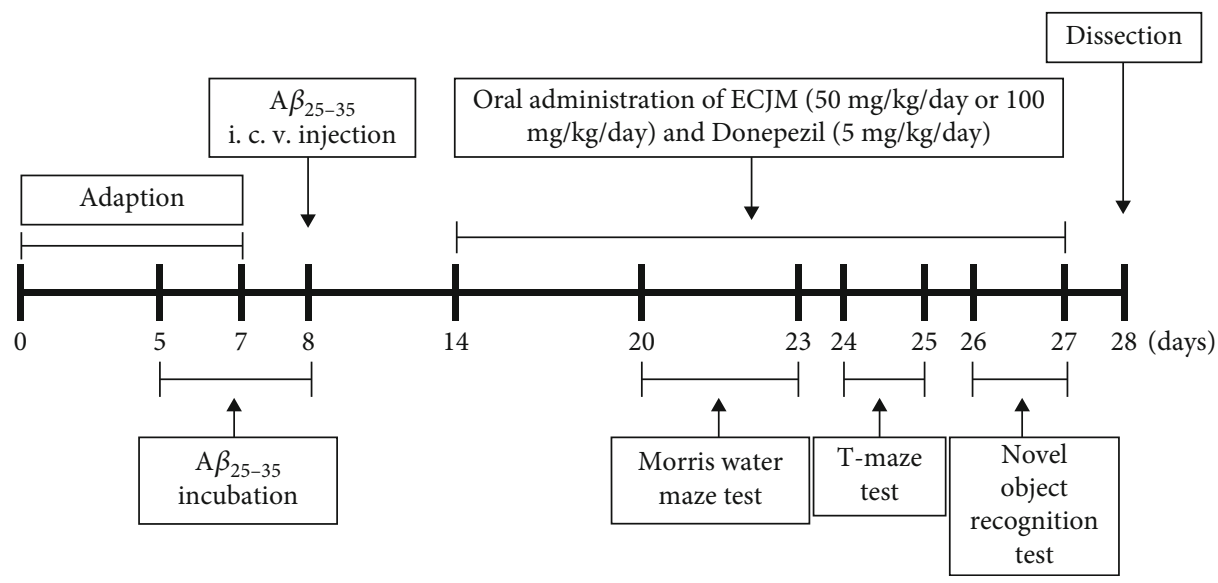

Figure 1: Timeline of experiments.

a ratio of $3: 2$ and used to anesthetize the mice. After stereotactic coordination of the mice, $5 \mathrm{nM}$ of $\mathrm{A} \beta_{25-35}$ was injected intracerebroventricularly into the right ventricle at a rate of $5 \mu \mathrm{L} / 3 \mathrm{~min}$ (anterior and posterior, $-0.8 \mathrm{~mm}$; posterolateral, $-1.5 \mathrm{~mm}$; dorsal and ventral, $-2.2 \mathrm{~mm}$ ) [24]. Mice in the control, ECJM, and donepezil groups were injected intracerebroventricularly with $\mathrm{A} \beta_{25-35}$ in the brain, while mice in the sham group were injected intracerebroventricularly with $0.9 \% \mathrm{NaCl}$.

2.5. T-Maze Test. The T-maze test was performed according to the method of Montgomery [25], with modifications. We used a T-shaped labyrinth device with a left arm, right arm, and starter box. They consist of black panels (the starting and goal stick length is $50 \mathrm{~cm}$, the width is $13 \mathrm{~cm}$, and the height is $20 \mathrm{~cm}$ ), and they are separated by black partitions on both sides. During the training session, the left arm was blocked in the T-maze, and the mouse was placed in the start box of the Tmaze and allowed to explore for $10 \mathrm{~min}$. After finishing the training session, the mice were returned to their cages. After $24 \mathrm{~h}$, mice were allowed to explore both the left and right arms of the T-maze for $10 \mathrm{~min}$, and then, the number of entries was counted. Spatial awareness (\%) was calculated as follows: (number of left-or right-arm mouse entries/ number of total-arm mouse entries) $\times 100 \%$.

2.6. Novel Object Recognition Test. The novel object recognition test was conducted based on the study of Bevins and Besheer [26]. During the training session, two identical objects $\left(A, A^{\prime}\right)$ were placed in the center of an open field box $(40 \times 40 \times 40 \mathrm{~cm})$ coated with black paint. The two objects remained at a fixed position during the experiment. Each mouse was placed in the center of the box and allowed to explore for $10 \mathrm{~min}$. The number of contacts per subject was also recorded. After $24 \mathrm{~h}$ of training session, one of the two objects was changed to a novel object $(\mathrm{A}, \mathrm{B})$ for the test session. Each mouse was placed and allowed to contact each object for $10 \mathrm{~min}$. The number of contacts with familiar (A) and novel (B) objects was recorded. The novel object cognitive function (\%) was calculated as follows: (the number of contacts with the familiar or novel object/the total number of contacts with the two objects) $\times 100 \%$.
2.7. Morris Water Maze Test. The Morris water maze test was performed by Morris [27] with slight modifications. The equipment consisted of round obstacles $(80 \mathrm{~cm}$ in diameter and $40 \mathrm{~cm}$ in height) and was randomly divided into four equal parts. Each quadrant had a different poster at the center of the wall as a visual cue for navigation. The equipment was filled with invisible water, and the water temperature was maintained at $22 \pm 2^{\circ} \mathrm{C}$. The escape platform ( $8 \mathrm{~cm}$ in diameter) was set at the center of one of the quadrants, so that it was in a fixed position approximately $1 \mathrm{~cm}$ below the water surface. Mice were trained three times a day for three days. During the training period, mice were placed in the water facing the wall of the pool and allowed to swim for a maximum of $60 \mathrm{~s}$ to find a hidden platform. If the mouse could not find the hidden platform, it was guided to stay on the platform for $15 \mathrm{~s}$. After training, the mice were returned to their cages. During the test session, the experiment was performed as described previously. In the secondary test, the platform was removed, and each mouse was allowed to explore the pool for $60 \mathrm{~s}$. The mice searched for the target quadrant where the platform was placed, and then, the percentage of time spent in the target quadrant was calculated. In the final test, the water was replaced with clean water, and the time to reach the exposed platform was measured.

2.8. Measurement of NO Scavenging Activity. NO production in tissue was measured using the method established by Bryan and Grisham [28]. After the behavioral experiment was completed, the mice were anesthetized under $\mathrm{CO}_{2}$, and the brain, liver, and kidneys were immediately removed. The tissues in $0.9 \% \mathrm{NaCl}$ were homogenized, and $150 \mu \mathrm{L}$ of tissue homogenate was mixed with $130 \mu \mathrm{L}$ of DW for the measurement of NO. Afterwards, $100 \mu \mathrm{L}$ of the mixture was added to an equal volume of Griess reagent for the reaction. The absorbance of the mixture was measured at $540 \mathrm{~nm}$ wavelength. The level of NO production was calculated using a standard curve for sodium nitrite.

2.9. Measurement of Lipid Peroxidation. Lipid peroxidation was measured using the method established by Ohkawa et al. [29]. The tissues were homogenized in $20 \%$ phosphoric 
acid, $46 \mathrm{mM}$ TBA solution, and $920 \mathrm{mM}$ TCA solution. The mixture was boiled at $100^{\circ} \mathrm{C}$ for $20 \mathrm{~min}$ and immediately placed on ice. Butanol $(7 \mathrm{~mL})$ was added to the mixture and centrifuged at $3,000 \mathrm{rpm}$ for $10 \mathrm{~min}$. The supernatant was removed to measure the absorbance at $540 \mathrm{~nm}$. Lipid peroxidation levels were calculated using the MDA standard curve.

2.10. Statistical Analysis. All results are expressed as the mean \pm standard deviation. Statistical significance was determined using one-way analysis of variance (ANOVA) followed by Duncan's multiple range test. In the T-maze and novel object recognition test, Student's $t$-test was used to compare the two conditions. Statistical significance was set at $P<0.05$.

\section{Results}

3.1. Effect of ECJM on Space Perceptive Ability. The results of the T-maze test are shown in Figure 2. The T-maze test is one of the methods used to evaluate the cognitive and memory abilities of mice in space exploration. The $\mathrm{A} \beta_{25-35^{-}}$ induced control group showed a $53.42 \%$ and $46.58 \%$ space exploration rate for the old and new routes, respectively. However, the space exploration of the new route was $64.61 \%$ in the sham group. The space exploration rate of the $\mathrm{A} \beta_{25-35}$-induced control group was significantly lower than that of the sham group. However, after oral administration of ECJM at doses of 50 and $100 \mathrm{mg} / \mathrm{kg} /$ day, the space exploration rates for the new route were $60.20 \%$ and $67.55 \%$, respectively. The group administered donepezil as a positive control showed a new route exploration rate of $63.44 \%$.

3.2. Effect of ECJM on Object Recognition Ability. During the training session, the mice did not show statistical significance for the recognition of two objects $\left(A, A^{\prime}\right)$. After $24 \mathrm{~h}$, one of the objects was changed into a different object (A, $\mathrm{B})$, and the results of the testing session are shown in Figure 3. The sham group of mice had a search rate of $69.79 \%$ for the novel object. Compared with the familiar object, the sham group showed more curiosity about the novel object. Conversely, the exploration of familiar and novel objects in the $\mathrm{A} \beta_{25-35}$-induced control group was $51.27 \%$ and $48.73 \%$, respectively, and there was no statistically significant difference between the novel and familiar objects. Concurrently, the mice that were administered ECJM (50 or $100 \mathrm{mg} / \mathrm{kg} /$ day) and donepezil $(5 \mathrm{mg} / \mathrm{kg} / \mathrm{day})$ displayed significantly increased cognitive ability toward novel objects. In particular, the ECJM100 group showed higher exploration of novel objects than the other groups.

3.3. Effect of ECJM on Learning and Memory Ability. The Morris water maze test was used to evaluate the effect of ECJM on memory and spatial learning abilities of mice. As shown in Figure $4(\mathrm{a})$, in the $\mathrm{A} \beta_{25-35}$-induced control group, the time required to reach the hidden platform during the training process for 3 days was the longest among all groups. In the test session on day 4, the sham, ECJM50, ECJM100, and donepezil groups reached the hidden platform in a

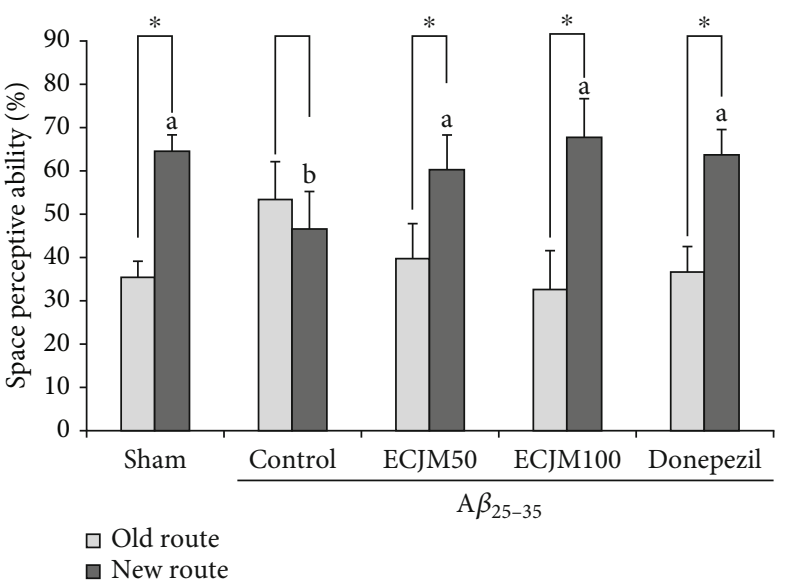

Figure 2: Effect of ECJM on T-maze test. (1) Sham group: injection of $0.9 \% \mathrm{NaCl}$ and oral administration of water. (2) Control group: injection of $\mathrm{A} \beta_{25-35}$ and oral administration of water. (3) ECJM50 group: injection of $\mathrm{A} \beta_{25-35}$ and oral administration of ECJM (50 mg/kg/day). (4) ECJM100 group: injection of $A \beta_{25-35}$ and oral administration of ECJM ( $100 \mathrm{mg} / \mathrm{kg} /$ day $)$. (5) Donepezil group: injection of $\mathrm{A} \beta_{25-35}$ and oral administration of donepezil $(5 \mathrm{mg} /$ $\mathrm{kg}$ /day). Values are the mean $\pm \mathrm{SD}$. One-way ANOVA was used to compare the mean values of groups, followed by Duncan's multiple-range test post hoc. Different alphabet letters ( $a, b)$ indicate statistically significant difference $(P<0.05)$. Mean values with the same letter are not significantly different. The asterisk $(*)$ represents the significant difference in space perceptive abilities with old and new routes by Student's $t$-test $(P<0.05)$.

shorter time than the control group. The total time for each group of mice to enter the target quadrant is indicated in Figure $4(\mathrm{~b})$. The $\mathrm{A} \beta_{25-35}$-induced control group had cognitive impairment, and the time to stay was shorter than that in the sham group. The mice in the ECJM50, ECJM100, and donepezil groups stayed for a longer time in the target quadrant compared with the control group. To investigate whether ECJM's learning and memory improvement effect on mice was related to the visual and athletic ability of mice, we also measured the latency to reach the exposed platform (Figure 4(d)). As shown in Figure 4(d), during the exposed platform test, no statistical significance was observed in any of the experimental groups, indicating that the improvement effect of ECJM on the learning and memory abilities in mice was unrelated to vision and motor ability.

3.4. Effect of ECJM on NO Production Induced by $A \beta_{25-35}$. The inhibitory effect of ECJM on NO production in the brain, liver, and kidneys is shown in Figure 5. The NO production of the sham group in the brain (Figure 5(a)) was $30.7 \mu \mathrm{mol} / \mathrm{L} / \mathrm{mg}$, while that of the control group was $40.89 \mu \mathrm{mol} / \mathrm{L} / \mathrm{mg}$. It could be seen that NO production significantly increased in the brain by the injection of $\mathrm{A} \beta_{25-35}$. Moreover, the NO production level in the ECJM50 and ECJM100 groups decreased to $40.3 \mu \mathrm{mol} / \mathrm{L} / \mathrm{mg}$ and $23.94 \mu \mathrm{mol} / \mathrm{L} / \mathrm{mg}$, respectively, and was significantly reduced to $23.80 \mu \mathrm{mol} / \mathrm{L} / \mathrm{mg}$ in the donepezil group. In the liver (Figure 5(b)), the NO production level in the sham group was $46.09 \mu \mathrm{mol} / \mathrm{L} / \mathrm{mg}$, while that in the control group 


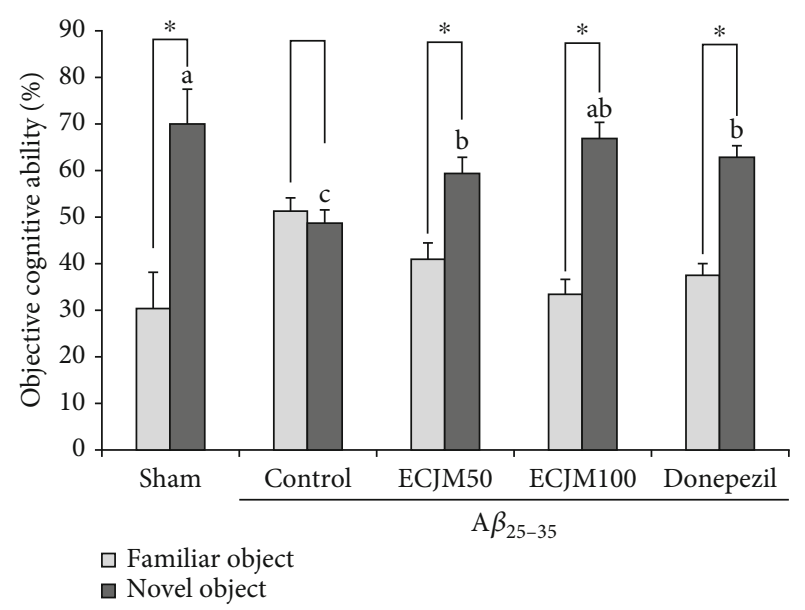

Figure 3: Effect of ECJM on novel objective recognition test. (1) Sham group: injection of $0.9 \% \mathrm{NaCl}$ and oral administration of water. (2) Control group: injection of $\mathrm{A} \beta_{25-35}$ and oral administration of water. (3) ECJM50 group: injection of $\mathrm{A} \beta_{25-35}$ and oral administration of ECJM ( $50 \mathrm{mg} / \mathrm{kg} /$ day). (4) ECJM100 group: injection of $\mathrm{A} \beta_{25-35}$ and oral administration of ECJM ( $100 \mathrm{mg} / \mathrm{kg} /$ day). (5) Donepezil group: injection of $\mathrm{A} \beta_{25-35}$ and oral administration of donepezil $(5 \mathrm{mg} / \mathrm{kg} /$ day). Values are the mean $\pm \mathrm{SD}$. One-way ANOVA was used to compare the mean values of groups, followed by Duncan's multiple-range test post hoc. Different alphabet letters ( $a, b$, and c) indicate statistically significant difference $(P<0.05)$. Mean values with the same letter are not significantly different. The asterisk $(*)$ represents the significant difference in object recognition ability with familiar and novel objects by Student's $t$-test $(P<0.05)$.

significantly increased to $56.86 \mu \mathrm{mol} / \mathrm{L} / \mathrm{mg}$. ECJM at a dose of $50 \mathrm{mg} / \mathrm{kg} /$ day showed no significant reduction of NO production, but ECJM at a dose of $100 \mathrm{mg} / \mathrm{kg} /$ day and in donepezil-administered groups reduced NO production to $50.67 \mu \mathrm{mol} / \mathrm{L} / \mathrm{mg}$ and $49.00 \mu \mathrm{mol} / \mathrm{L} / \mathrm{mg}$, respectively. In the kidney (Figure $5(\mathrm{c})$ ), NO production in the sham group was $50.7 \mu \mathrm{mol} / \mathrm{L} / \mathrm{mg}$, while NO production in the control group significantly increased to $66.18 \mu \mathrm{mol} / \mathrm{L} / \mathrm{mg}$. Further, the NO production in the ECJM50, ECJM100, and donepezil groups in the kidneys showed no significant difference when compared with the control group. These results indicated that the levels of NO in the brain, liver, and kidney were significantly increased by injection of $\mathrm{A} \beta_{25-35}$, and the administration of ECJM and donepezil inhibited NO production in tissues.

3.5. Effect of ECJM on Lipid Peroxidation Induced by $A \beta_{25-35}$. We measured the effect of ECJM on the lipid peroxidation of $\mathrm{A} \beta_{25-35}$-induced oxidative stress in the brain, liver, and kidney, and the results are shown in Figure 6. The MDA level in the sham group in the brain (Figure 6(a)) was $98.95 \mathrm{nmol} /$ $\mathrm{mg}$ protein, while that in the control group significantly increased to $110.69 \mathrm{nmol} / \mathrm{mg}$ protein. Moreover, the MDA levels in the ECJM50, ECJM100, and donepezil groups significantly reduced to $103.84,91.89$, and $101.41 \mathrm{nmol} / \mathrm{mg}$, respectively, compared with the control group. In particular, the MDA level in the ECJM100 group decreased markedly compared to the other groups. In the liver (Figure 6(b)), the MDA level in the sham group was $111.04 \mathrm{nmol} / \mathrm{mg}$ pro- tein, while that in the control group increased to $122.71 \mathrm{nmol} / \mathrm{mg}$ protein. The MDA levels in ECJM50, ECJM100, and donepezil groups significantly decreased to $116.56 \mathrm{nmol} / \mathrm{mg}, \quad 116.87 \mathrm{nmol} / \mathrm{mg}$, and $116.35 \mathrm{nmol} / \mathrm{mg}$, respectively, compared with the control group; these results showed that the MDA levels in the ECJM group underwent a similar reduction like the donepezil group. In the kidney (Figure 6(c)), the MDA level in the control group significantly increased to $83.73 \mathrm{nmol} / \mathrm{mg}$ protein. However, MDA levels in the ECJM100 and donepezil groups decreased to $68.56 \mathrm{nmol} / \mathrm{mg}$ and $69.38 \mathrm{nmol} / \mathrm{mg}$, respectively. The present results indicated that $\mathrm{A} \beta_{25-35}$ elevated lipid peroxidation in the brain, liver, and kidney, but oral administration of ECJM attenuated the lipid peroxidation caused by $\mathrm{A} \beta_{25-35}$.

\section{Discussion}

$\mathrm{AD}$ is characterized by the formation of senile plaques and neurofibrillary tangles in the brain with progressive cognitive impairment due to neuronal death, synaptic dysfunction, and oxidative stress [30]. Oxidative stress induced by the overproduction of ROS, such as hydrogen peroxide, NO, superoxide, and hydroxyl radicals, causes neuronal cell dysfunction or death [31]. Oxidative stress is regulated by homeostasis between oxidants and antioxidants, but overproduction of ROS leads to oxidative modification of proteins, lipids, RNA, DNA, and other biomolecules [32]. The oxidative stress induced by $\mathrm{A} \beta$ in the brain is consistent with the injury described in AD [33]. In particular, APP-derived $\mathrm{A} \beta$ peptides are inserted into the bilayer of neurons and glial membranes, thereby generating oxygen-dependent free radicals [34]. $\mathrm{A} \beta_{25-35}$, a core toxic fragment in $\mathrm{A} \beta$ peptide, leads to cognitive deficits, memory impairment, inflammation, and oxidative stress in the mouse brain [35]. Furthermore, previous studies have reported that i.c.v. injection of $\mathrm{A} \beta_{25}$ 35 is responsible for cognitive impairment in the mouse brain [36]. Therefore, in the present study, we used i.c.v. injection of $\mathrm{A} \beta_{25-35}$ to induce cognitive impairment in an $\mathrm{AD}$ mouse model.

Donepezil, which is an acetylcholinesterase inhibitor, is a representative drug used for $\mathrm{AD}$ treatment by approved the Food and Drug Administration [37]. The concentration of donepezil used in present study was determined on the basis of other reports on animal experiments. Several behavioral studies have proved that donepezil treatment with dose ranging of $3-10 \mathrm{mg} / \mathrm{kg}$ prevented the learning and memory deficits by scopolamine treatment [38]. Additionally, previous studies investigated the concentration of donepezil as the most common on $3-5 \mathrm{mg} / \mathrm{kg} /$ day by oral administration [39]. Su et al. [40] indicated that oral administration of donepezil $(5 \mathrm{mg} / \mathrm{kg} /$ day) improved the decreased level of choline acetyltransferase in isoflurane-exposed mice. Therefore, donepezil was treated at $5 \mathrm{mg} / \mathrm{kg} /$ day in the present study.

Plant-derived constituents are separated by solvent extraction, and the extract yields and biological activities of plant substances are strongly dependent on the features of the extracting solvent [41]. Solvents frequently used in extraction are polar (e.g., EtOH, methyl alcohol, and water), intermediate polar (e.g., acetone and dichloromethane), and 


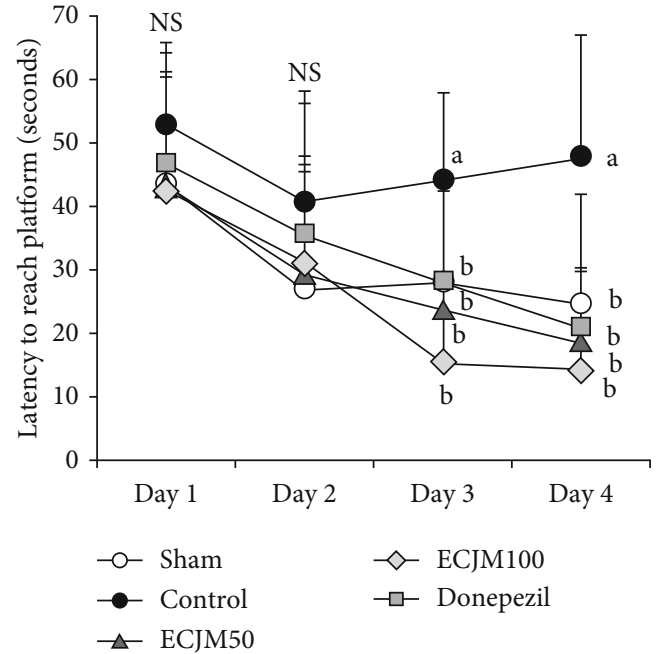

(a)

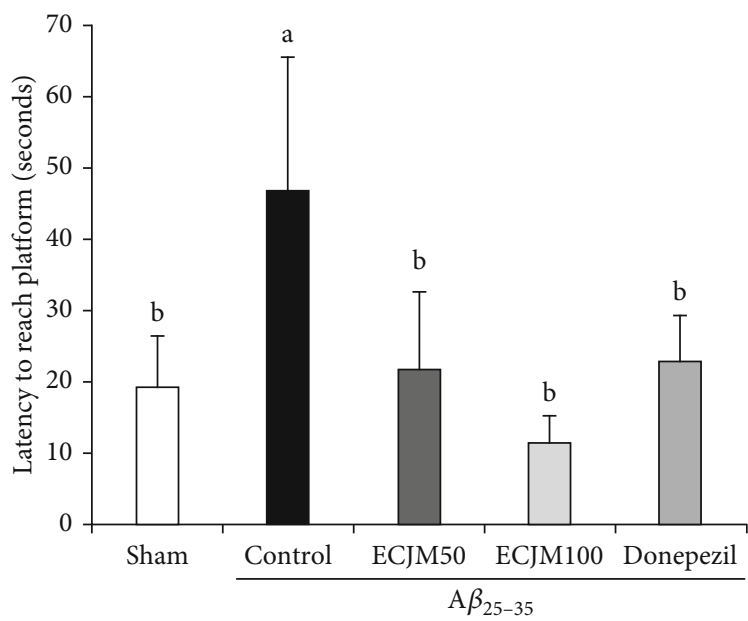

(c)

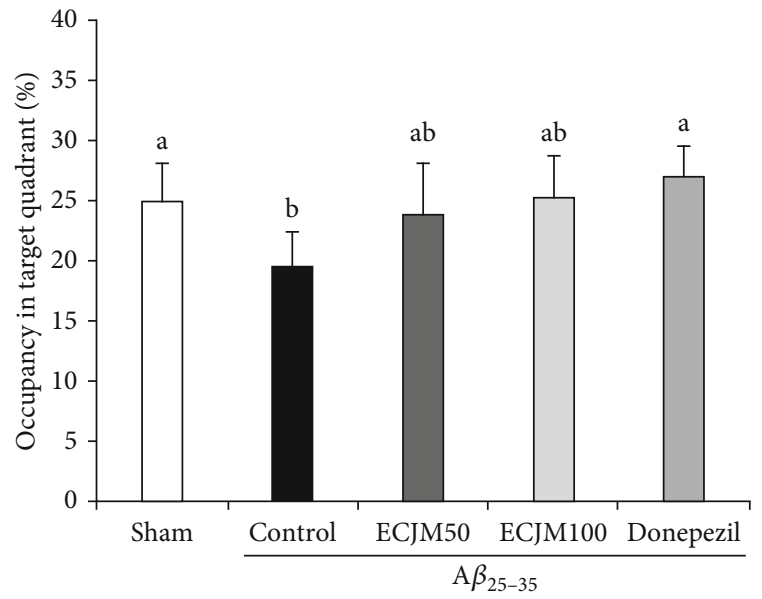

(b)

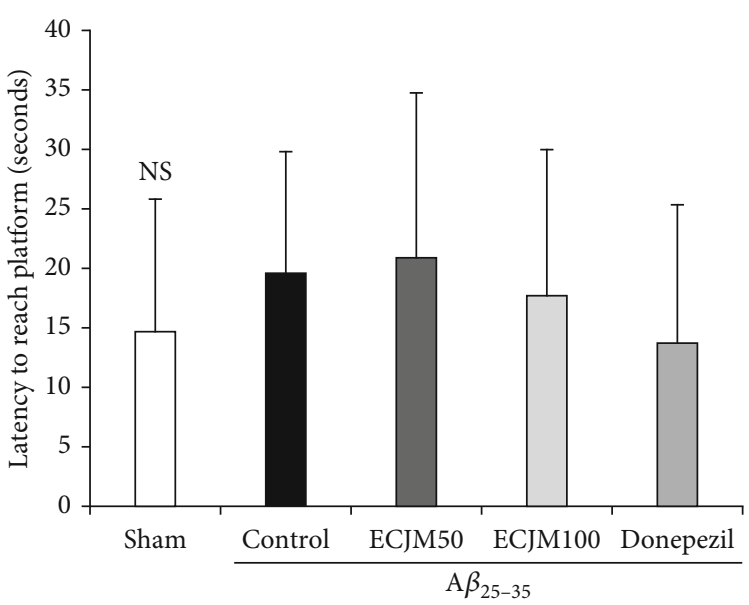

(d)

FIGURE 4: Effect of ECJM on Morris water maze test. (a) Effect of ECJM on escape latency in the Morris water maze test. (b) Effect of ECJM on occupancy time of the target quadrant in the Morris water maze test. (c) Effect of ECJM on latency to reach a hidden platform. (d) Effect of ECJM on latency to reach an exposed platform. (1) Sham group: injection of $0.9 \% \mathrm{NaCl}$ and oral administration of water. (2) Control group: injection of $\mathrm{A} \beta_{25-35}$ and oral administration of water. (3) ECJM50 group: injection of A $\beta_{25-35}$ and oral administration of ECJM $(50 \mathrm{mg} / \mathrm{kg} / \mathrm{day})$. (4) ECJM100 group: injection of $\mathrm{A} \beta_{25-35}$ and oral administration of ECJM (100 mg/kg/day). (5) Donepezil group: injection of $\mathrm{A} \beta_{25-35}$ and oral administration of donepezil $(5 \mathrm{mg} / \mathrm{kg} / \mathrm{day})$. Values are the mean $\pm \mathrm{SD}$. One-way ANOVA was used to compare the mean values of groups, followed by Duncan's multiple-range test post hoc. Different alphabet letters (a, b) indicate statistically significant difference $(P<0.05)$. Mean values with the same letter are not significantly different. NS: nonsignificance.

nonpolar (e.g., $n$-hexane and chloroform). EtOH and methyl alcohol have been widely applied to extract all primary (e.g., carbohydrates, organic and amino acids, and vitamins) and secondary metabolites, especially phenolic compounds and flavonoids from various plants $[42,43]$. Emerging evidence has shown that ECJM from EtOH extract has relative inhibitory effects against $\mathrm{A} \beta_{25-35}$-induced cytotoxicity in neurons and glial cells, as well as against aldose reductase, $\alpha$-glucosidase, oxidative stress, and inflammation $[14,17,18,20,21$, 44]. Hence, in the present study, EJCM from EtOH extract was used to investigate the improvement effects of $\mathrm{A} \beta_{25-35^{-}}$ induced cognitive impairment.
CJM is a medicinal plant with anti-inflammatory, antitumor, antioxidant, and antidiabetic effects $[14,16,17]$. In particular, CJM has been reported to inhibit ROS production and BACE1 activity, indicating that CJM prevents oxidative stress-related diseases such as AD [17, 45]. Additionally, treatment with CJM increases cell viability and reduced ROS production in C6 glial cells induced by $\mathrm{A} \beta_{25-35}$ [44]. However, the protective effect of ECJM against cognitive impairment in an $\mathrm{A} \beta$-induced in vivo $\mathrm{AD}$ mouse model has not been reported. In our current study, ECJM at doses of 50 and $100 \mathrm{mg} / \mathrm{kg} /$ day was orally administered to an $\mathrm{AD}$ mouse model induced by $\mathrm{A} \beta_{25-35}$, and we confirmed its 


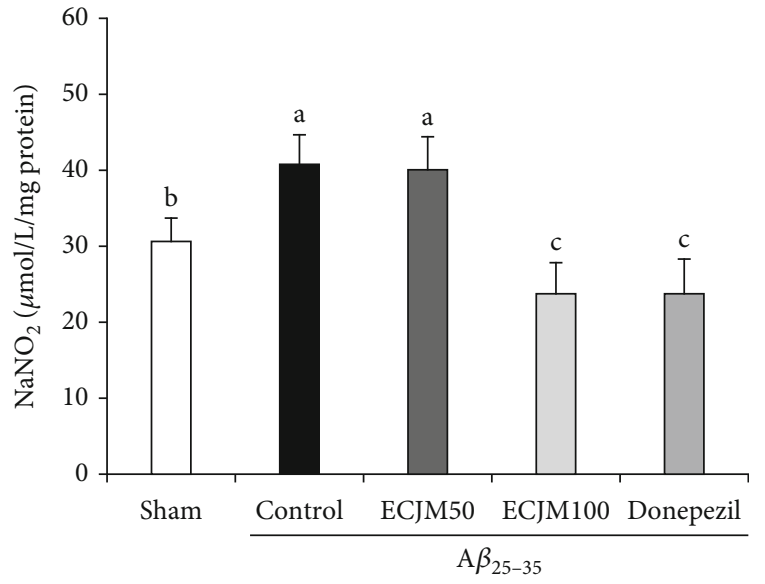

(a)

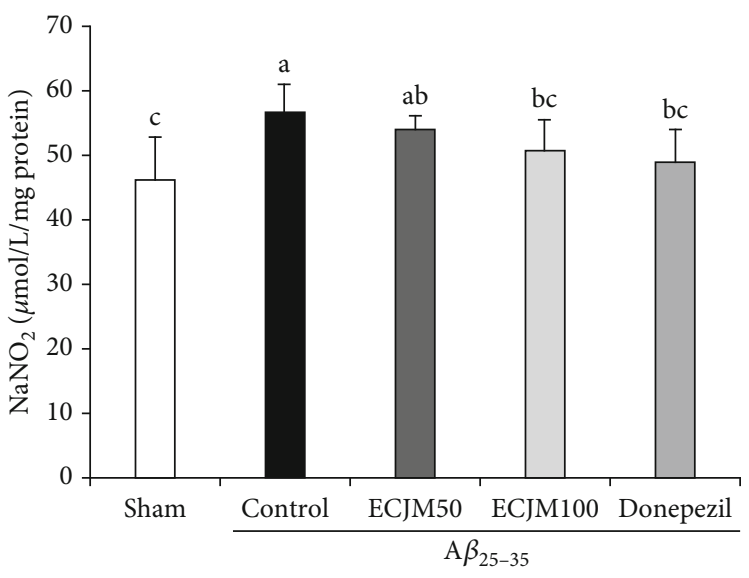

(b)

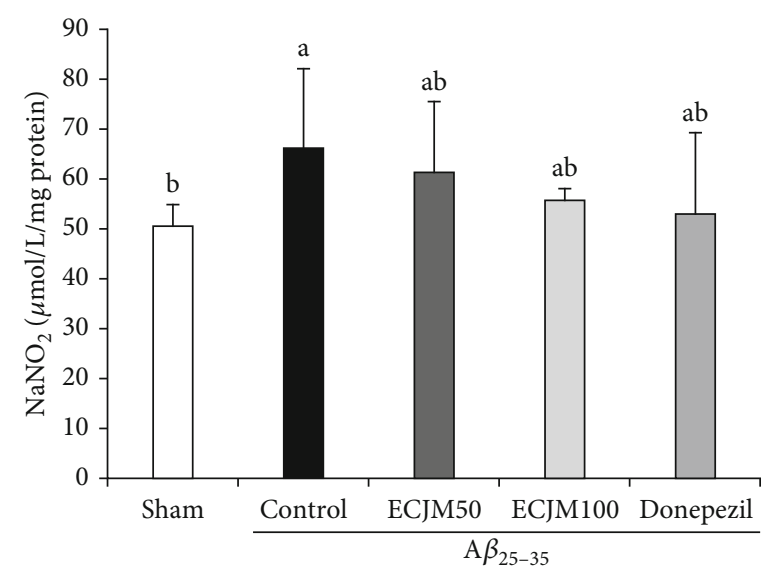

(c)

FIGURE 5: Effect of ECJM on A $\beta_{25-35}$-induced NO production in the brain (a), liver (b), and kidney (c). (1) Sham group: injection of $0.9 \%$ NaCl and oral administration of water. (2) Control group: injection of $\mathrm{A} \beta_{25-35}$ and oral administration of water. (3) ECJM50 group: injection of $\mathrm{A} \beta_{25-35}$ and oral administration of ECJM (50 mg/kg/day). (4) ECJM100 group: injection of A $\beta_{25-35}$ and oral administration of ECJM (100 mg/kg/day). (5) Donepezil group: injection of $\mathrm{A} \beta_{25-35}$ and oral administration of donepezil ( $5 \mathrm{mg} / \mathrm{kg} /$ day). Values are the mean \pm SD. One-way ANOVA was used to compare the mean values of groups, followed by Duncan's multiple-range test post hoc. Different alphabet letters ( $a, b$, and $c)$ indicate statistically significant difference $(P<0.05)$. Mean values with the same letter are not significantly different.

cognitive improvement effects and protective mechanisms against $\mathrm{AD}$ in an in vivo system.

$\mathrm{A} \beta$-exposed mice can experience severe deficits in spatial memory and learning, but not locomotor and sensorimotor activities [46, 47]. Nga et al. [46] reported that $\mathrm{A} \beta$ exposure led to a complete disruption of object recognition and serious detriment in the water maze but did not affect spontaneous locomotor activity or sensorimotor gating in rats. In the present study, we designed behavioral experiments to confirm the recognition, memory, and learning abilities of an $\mathrm{A} \beta$-exposed AD mouse model.

The novel object recognition test is a task based on spontaneous behaviors and is used to evaluate novel object recognition impairment in rodents [48]. When setting a novel object after exposure to familiar objects, rodents spend more time exploring novel objects than familiar objects [49]. We conducted a novel object recognition test to evaluate the protective effect of ECJM on novel object recognition impairment in an $\mathrm{A} \beta_{25-35}$-induced mouse model. Our results showed that there was no statistically significant dif- ference between the familiar and novel objects in the $\mathrm{A} \beta_{25}$ 35 -induced control group. Similarly, previous studies demonstrated that $\mathrm{A} \beta_{25-35}$-induced cognitive impairment mice did not show statistical significance in differentiating between familiar and novel objects, indicating that the cognitive impairment mouse model was successfully induced in this study. Several studies have reported that AD mice who received oral administration of anti-AD materials such as donepezil, galantamine, and memantine spent more time exploring novel objects $[50,51]$. In our study, oral administration of ECJM at a dose of $100 \mathrm{mg} / \mathrm{kg} /$ day to AD mice induced a higher awareness of novel objects compared with the control group, indicating that oral administration of ECJM improves novel object recognition in $\mathrm{A} \beta_{25-35}$-induced mice.

The T-maze test is widely used to evaluate spatial memory ability [52], and it has been reported that $\mathrm{A} \beta_{25-35}$-induction of mice leads to spatial memory deficits. In the present study, the $\mathrm{A} \beta_{25-35}$-induced control group showed no significant difference in differentiating between the new and old 


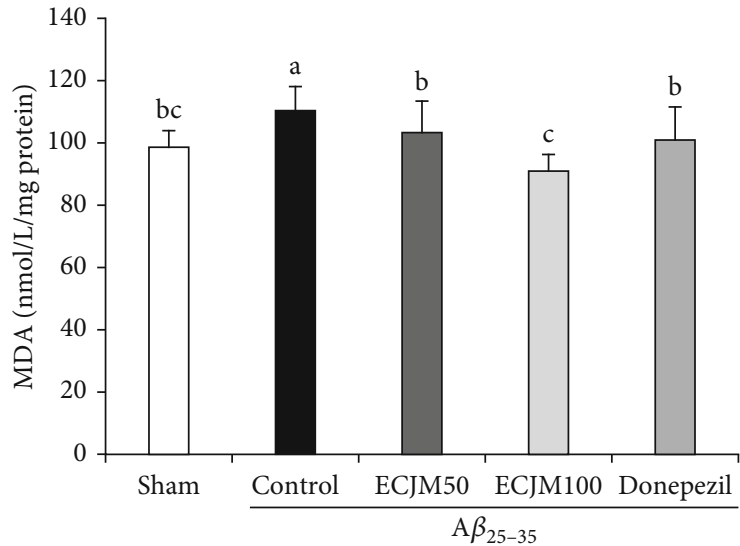

(a)

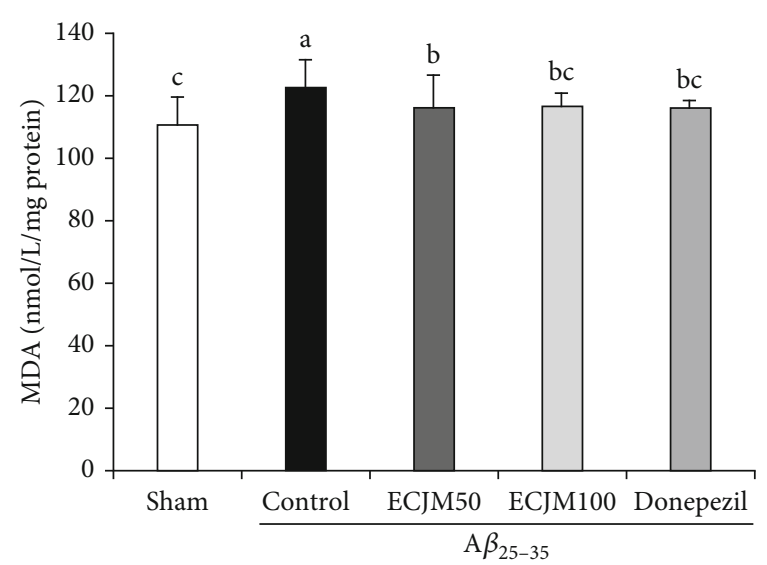

(b)

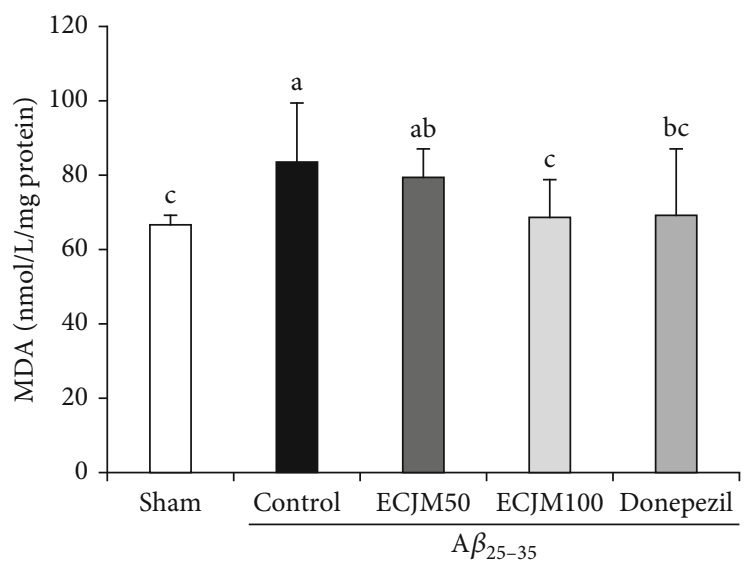

(c)

Figure 6: Effect of ECJM on A $\beta_{25-35}$-induced lipid peroxidation in the brain (a), liver (b), and kidney (c). (1) Sham group: injection of $0.9 \% \mathrm{NaCl}$ and oral administration of water. (2) Control group: injection of $\mathrm{A} \beta_{25-35}$ and oral administration of water. (3) ECJM50 group: injection of $\mathrm{A} \beta_{25-35}$ and oral administration of ECJM (50 mg/kg/day). (4) ECJM100 group: injection of A $\beta_{25-35}$ and oral administration of ECJM (100 mg/kg/day). (5) Donepezil group: injection of $\mathrm{A} \beta_{25-35}$ and oral administration of donepezil ( $5 \mathrm{mg} / \mathrm{kg} /$ day). Values are the mean $\pm \mathrm{SD}$. One-way ANOVA was used to compare the mean values of groups, followed by Duncan's multiple-range test post hoc. Different alphabet letters (a, b, and $c)$ indicate statistically significant difference $(P<0.05)$. Mean values with the same letter are not significantly different.

routes. However, in the spatial exploration of the new and old routes, the ECJM50 and ECJM100 groups had a high exploration rate for the new route compared with the control group. Moreover, the ECJM100 group showed a higher spatial exploration rate than the donepezil-administered group. Therefore, our results indicate that oral administration of ECJM has a protective effect on spatial memory deficits in $\mathrm{A} \beta_{25-35}$-induced mice.

To evaluate the long-term memory ability of ECJM in the $\mathrm{A} \beta_{25-35}$-induced mouse model, we performed the Morris water maze test. Previous studies have reported that mice induced by $\mathrm{A} \beta_{25-35}$ exhibited learning and memory impairment by reducing the time to reach the hidden platform in the Morris water maze $[5,53]$. The control group took a longer time to find the hidden escape platform, indicating that the long-term spatial memory of the mice was impaired after $\mathrm{A} \beta_{25-35}$ injection. Further, the ECJM50 and ECJM100 groups could quickly find the hidden platform compared with the control group. After removing the hidden platform under the water, the ECJM50 and ECJM100 mice spent more time than the control group in the area where the hidden platform was placed. At the same time, in the experiment of exposing the platform, there was no statistical significance regarding the time for the mice to find the platform among all groups. These results indicate that ECJM can improve long-term spatial memory impairment caused by $\mathrm{A} \beta_{25-35}$ in mice, which is related to memory function, but has no effect on swimming and visual abilities.

$\mathrm{NO}$ acts as a neurotransmitter that produces oxidants in the brain. An increased level of NO in the brain leads to oxidative stress-mediated cell apoptosis in neurons and is largely involved in the dysfunction of learning and memory $[54,55]$. At low concentrations, NO affects the oxidation of the substrate, but NO at high concentrations affects the nitration of proteins and neuronal death, thus suggesting that increased NO concentration plays a neurotoxic role [56]. The overproduction of NO not only exacerbates the inflammatory response but also promotes neurodegeneration [57]. A $\beta$-mediated neurotoxicity is caused by overproduction of $\mathrm{NO}$, suggesting that production of $\mathrm{NO}$ may be a 
mediator in $\mathrm{A} \beta$-related $\mathrm{AD}$ [58]. The reaction of peroxynitrite with protein tyrosine residues resulted in high levels of nitrotyrosine in the brains of $\mathrm{AD}$ patients, suggesting that NO participates in the development of $\mathrm{AD}$ [59]. NO induced by $\mathrm{A} \beta_{25-35}$ releases nitrite $\left(\mathrm{NO}_{2}{ }^{-}\right)$and nitrate $\left(\mathrm{NO}_{3}{ }^{-}\right)$in tissues such as the brain, liver, and kidney. Therefore, the measurements of $\mathrm{NO}_{2}^{-}$and $\mathrm{NO}_{3}^{-}$concentrations are usually used as indicators of NO production in $\mathrm{AD}$ mice [60]. The Griess reaction, which reacts with $\mathrm{NO}_{2}{ }^{-}$in mouse tissue homogenates, is widely used as a measurement of the $\mathrm{NO}_{2}{ }^{-}$ level [61]. Studies have shown that excessive NO production in $\mathrm{A} \beta$-induced mice and neuronal cells induces cognitive impairment and mitochondrial apoptosis [62]. Moreover, an NO-related research demonstrated that inhibitors of NO synthesis attenuated memory deficits in arsenicinduced rodents [63]. Furthermore, a reliable study indicated that the injection of $\mathrm{A} \beta$ in the brain of rats damaged spatial learning and memory and produced a high NO concentration [35]. In our study, the protective effects of ECJM on $\mathrm{A} \beta_{25-35}$-induced oxidative stress in the mouse brain, liver, and kidney were investigated. Higher NO production was observed in the $\mathrm{A} \beta_{25-35}$-induced group in this study. Conversely, the ECJM50 and ECJM100 groups showed significantly decreased NO production in the brain and liver. These results indicate that oral administration of ECJM attenuated oxidative stress by inhibiting NO levels.

Oxygen and polyunsaturated fatty acids (PUFA) are widely found in the lipid bilayer of the brain, and the interaction between PUFA and free radicals leads to lipid peroxidation [64]. Lipid peroxidation and $\mathrm{A} \beta$ accumulation have been observed in patients with $\mathrm{AD}$. Additionally, lipid peroxidation leads to $\mathrm{A} \beta$ accumulation and plays a role in oxidative stress-induced cognitive impairments, which results from the atrophy and death of neurons in the brain [65]. As reported in previous papers, suppression of lipid peroxidation using antioxidants such as $\alpha$-tocopherol and docosahexaenoic acid is an effective treatment for cognitive dysfunction associated with $\mathrm{AD}$ symptoms, including memory and learning ability $[66,67]$. Several studies have reported a positive correlation between $\mathrm{NO}$ and lipid peroxidation. In previous studies using animal models of $\mathrm{AD}, \mathrm{NO}$ and lipid peroxidation can cause $\mathrm{A} \beta$ accumulation during the progression of $\mathrm{AD}[68]$.

MDA is a product of peroxidation of PUFAs, and the level of MDA indicates the level of lipid peroxidation [69]. Studies have reported an increase in MDA levels in the AD brain, and this has been considered a biomarker of lipid peroxidation [70]. Our results showed that MDA levels in the $\mathrm{A} \beta_{25-35^{-}}$ induced control group were significantly increased in the brain, liver, and kidney, compared with those in the sham group. Furthermore, the ECJM50 and ECJM100 groups showed significantly decreased MDA levels in the brain and liver tissues, compared with the control group. Therefore, administration of ECJM inhibited oxidative stress by reducing lipid peroxidation in $\mathrm{A} \beta_{25-35}$-induced $\mathrm{AD}$ mouse.

\section{Conclusions}

The results of the present study showed that oral administration of ECJM $(50 \mathrm{mg} / \mathrm{kg} /$ day and $100 \mathrm{mg} / \mathrm{kg} /$ day $)$ improved cognitive abilities by inhibiting oxidative stress in $\mathrm{A} \beta_{25-35^{-}}$ induced mice. This study suggests that CJM could be useful as an agent for the prevention and treatment of $\mathrm{AD}$.

\section{Data Availability}

The data used to support the findings of this study are included within the article.

\section{Conflicts of Interest}

The authors declare that there are no conflicts of interest.

\section{Authors' Contributions}

Qi Qi Pang and Ji-Hyun Kim contributed equally to this study.

\section{Acknowledgments}

This research was supported by the Basic Science Research Program through the National Research Foundation of Korea (NRF) funded by the Ministry of Education (No. 2018R1D1A1B07043784).

\section{References}

[1] X. Sun, W. D. Chen, and Y. D. Wang, " $B$-Amyloid: the key peptide in the pathogenesis of Alzheimer's disease," Frontiers in Pharmacology, vol. 6, p. Article 221, 2015.

[2] K. Blennow and H. Zetterberg, "Biomarkers for Alzheimer's disease: current status and prospects for the future," Journal of Internal Medicine, vol. 284, no. 6, pp. 643-663, 2018.

[3] J. Hardy and D. J. Selkoe, "The amyloid hypothesis of Alzheimer's disease: progress and problems on the road to therapeutics," Science, vol. 297, no. 5580, pp. 353-356, 2002.

[4] D. M. Walsh and D. J. Selkoe, "Amyloid $\beta$-protein and beyond: the path forward in Alzheimer's disease," Current Opinion in Neurobiology, vol. 61, pp. 116-124, 2020.

[5] A. Nunomura, R. J. Castellani, X. Zhu, P. I. Moreira, G. Perry, and M. A. Smith, "Involvement of oxidative stress in Alzheimer disease," Journal of Neuropathology \& Experimental Neurology, vol. 65, no. 7, pp. 631-641, 2006.

[6] H. F. Poon, V. Calabrese, G. Scapagnini, and D. A. Butterfield, "Free radicals and brain aging," Clinics in Geriatric Medicine, vol. 20, no. 2, pp. 329-359, 2004.

[7] B. Halliwell, "Oxidative stress and neurodegeneration: where are we now?," Journal of Neurochemistry, vol. 97, no. 6, pp. 1634-1658, 2006.

[8] M. A. Lovell, J. D. Robertson, W. J. Teesdale, J. L. Campbell, and W. R. Markesbery, "Copper, iron and zinc in Alzheimer's disease senile plaques," Journal of the Neurological Sciences, vol. 158, no. 1, pp. 47-52, 1998.

[9] C. Behl, J. B. Davis, R. Lesley, and D. Schubert, "Hydrogen peroxide mediates amyloid $\beta$ protein toxicity," Cell, vol. 77, no. 6 , pp. 817-827, 1994.

[10] M. Belkhelfa, H. Rafa, O. Medjeber et al., "IFN- $\gamma$ and TNF- $\alpha$ are involved during Alzheimer disease progression and correlate with nitric oxide production: a study in Algerian patients," Journal of Interferon and Cytokine Research, vol. 34, no. 11, pp. 839-847, 2014. 
[11] Z. Cai, B. Zhao, and A. Ratka, "Oxidative stress and $\beta$-amyloid protein in Alzheimer's disease," Neuromolecular Medicine, vol. 13, no. 4, pp. 223-250, 2011.

[12] B. G. Pérez-Nievas and A. Serrano-Pozo, "Editorial: the role of glia in Alzheimer's disease," Frontiers in Neurology, vol. 9, p. Article 1161, 2019.

[13] S. Liu, J. Zhang, D. Li et al., “Anticancer activity and quantitative analysis of flavone of Cirsium japonicum DC," Natural Product Research, vol. 21, no. 10, pp. 915-922, 2007.

[14] H. A. Jung, S. E. Jin, B.-S. Min, B.-W. Kim, and J. S. Choi, "Anti-inflammatory activity of Korean thistle _Cirsium maackii_and its major flavonoid, luteolin 5- _O_ -glucoside," Food and Chemical Toxicology, vol. 50, no. 6, pp. 2171-2179, 2012.

[15] S. Liu, X. Luo, D. Li et al., "Tumor inhibition and improved immunity in mice treated with flavone from _Cirsium japonicum_ DC, International Immunopharmacology, vol. 6, no. 9, pp. 1387-1393, 2006.

[16] K.-K. Oh, M. Adnan, and D.-H. Cho, "Network pharmacology-based study to uncover potential pharmacological mechanisms of Korean thistle (Cirsium japonicum var. maackii (maxim.) Matsum.) flower against cancer," Molecules, vol. 26, no. 19, p. 5904, 2021.

[17] A. Wagle, S. H. Seong, S. Shrestha, H. A. Jung, and J. S. Choi, "Korean thistle (Cirsium japonicum var. maackii (Maxim.) Matsum.): a potential dietary supplement against diabetes and Alzheimer's disease," Molecules, vol. 24, no. 3, p. article $649,, 2019$.

[18] J. Lee, J. P. Rodriguez, K. H. Lee et al., "Determination of flavonoids from Cirsium japonicum var. maackii and their inhibitory activities against aldose reductase," Applied Biological Chemistry, vol. 60, no. 5, pp. 487-496, 2017.

[19] G. Bhatarrai, S. H. Seong, H. A. Jung, and J. S. Choi, "Isolation and quantitative analysis of BACE1 inhibitory compounds fromCirsium maackiiFlower," Natural Product Sciences, vol. 25, no. 4, pp. 326-333, 2019.

[20] M. J. Kim, J.-H. Kim, J. H. Kim, S. Lee, and E. J. Cho, “Amelioration effects ofCirsium japonicumvar.maackiiextract/fractions on amyloid beta $_{25-35}$-induced neurotoxicity in $\mathrm{SH}$ SY5Y cells and identification of the main bioactive compound," Food \& Function, vol. 11, no. 11, pp. 9651-9661, 2020.

[21] J. P. Rodriguez, Y. K. Lee, D. G. Woo et al., "Flavonoids from Cirsium japonicum var. maackii pappus as inhibitors of aldose reductase and their simultaneous determination," Chemical Papers, vol. 72, no. 1, pp. 81-88, 2018.

[22] A. Y. Lee, M. J. Kim, S. Lee, J. S. Sim, and E. J. Cho, "Protective effect of Cirsium japonicum var. maackii against oxidative stress in C6 glial cells, Korean," Journal of Agricultural Science, vol. 45, no. 3, pp. 509-519, 2018.

[23] T. Maurice, B. P. Lockhart, and A. Privat, "Amnesia induced in mice by centrally administered $\beta$-amyloid peptides involves cholinergic dysfunction," Brain Research, vol. 706, no. 2, pp. 181-193, 1996.

[24] S. E. Laursen and J. K. Belknap, "Intracerebroventricular injections in mice: Some methodological refinements," Journal of Pharmacological Methods, vol. 16, no. 4, pp. 355-357, 1986.

[25] K. C. Montgomery, "A test of two explanations of spontaneous alternation," Journal of Comparative and Physiological Psychology, vol. 45, no. 3, pp. 287-293, 1952.

[26] R. A. Bevins and J. Besheer, "Object recognition in rats and mice: a one-trial non-matching-to-sample learning task to study 'recognition memory'," Nature Protocols, vol. 1, pp. 1306-1311, 2004.

[27] R. Morris, "Developments of a water-maze procedure for studying spatial learning in the rat," Journal of Neuroscience Methods, vol. 11, no. 1, pp. 47-60, 1984.

[28] N. S. Bryan and M. B. Grisham, "Methods to detect nitric oxide and its metabolites in biological samples," Free Radical Biology and Medicine, vol. 43, no. 5, pp. 645-657, 2007.

[29] H. Ohkawa, N. Ohishi, and K. Yagi, "Assay for lipid peroxides in animal tissues by thiobarbituric acid reaction," Analytical Biochemistry, vol. 95, no. 2, pp. 351-358, 1979.

[30] J. W. Ashford, “The Dichotomy of Alzheimer's Disease Pathology: Amyloid- $\beta$ and Tau," Journal of Alzheimer's Disease, vol. 68, no. 1, pp. 77-83, 2019.

[31] K. J. Barnham, C. L. Masters, and A. I. Bush, "Neurodegenerative diseases and oxidative stress," Nature Reviews Drug Discovery, vol. 3, no. 3, pp. 205-214, 2004.

[32] H. M. Gao, H. Zhou, and J. S. Hong, "NADPH oxidases: novel therapeutic targets for neurodegenerative diseases," Trends in Pharmacological Sciences, vol. 33, no. 6, pp. 295-303, 2012.

[33] S. Miranda, C. Opazo, L. F. Larrondo et al., "The role of oxidative stress in the toxicity induced by amyloid $\beta$-peptide in Alzheimer's disease," Progress in Neurobiology, vol. 62, no. 6, pp. 633-648, 2000.

[34] S. Varadarajan, S. Yatin, M. Aksenova, and D. A. Butterfield, "Review: Alzheimer's Amyloid $\beta$-Peptide-Associated Free Radical Oxidative Stress and Neurotoxicity," Journal of Structural Biology, vol. 130, no. 2-3, pp. 184-208, 2000.

[35] I. D. Limón, A. Díaz, L. Mendieta et al., “Amyloid- $\beta_{25-35}$ impairs memory and increases NO in the temporal cortex of rats," Neuroscience Research, vol. 63, no. 2, pp. 129-137, 2009.

[36] M. Y. Stepanichev, I. M. Zdobnova, I. I. Zarubenko et al., "Amyloid-beta(25-35)-induced memory impairments correlate with cell loss in rat hippocampus," Physiology \& Behavior, vol. 80, no. 5, pp. 647-655, 2004.

[37] M. B. Colovic, D. Z. Krstic, T. D. Lazarevic-Pasti, A. M. Bondzic, and V. M. Vasic, "Acetylcholinesterase inhibitors: pharmacology and toxicology," Current Neuropharmacology, vol. 11, no. 3, pp. 315-335, 2013.

[38] A. T. Mugwagwa, L. L. Gadaga, W. Pote, and D. Tagwireyi, "Anti-amnesic effects of a hydroethanolic extract of Crinum macowanii on scopolamine-induced memory impairment in mice," Journal of Neurodegenerative Diseases, vol. 2015, Article ID 242505, 2015.

[39] G. Saxena, S. P. Singh, R. Agrawal, and C. Nath, "Effect of donepezil and tacrine on oxidative stress in intracerebral streptozotocin-induced model of dementia in mice," European Journal of Pharmacology, vol. 581, no. 3, pp. 283-289, 2008.

[40] D. Su, Y. Zhao, B. Wang et al., "Isoflurane-induced spatial memory impairment in mice is prevented by the acetylcholinesterase inhibitor donepezil," PLoS One, vol. 6, no. 11, p. Article e27632, 2011.

[41] S. Arabshahi-Delouee and A. Urooj, “Antioxidant properties of various solvent extracts of mulberry (Morus indica L.) leaves," Food Chemistry, vol. 102, no. 4, pp. 1233-1240, 2007.

[42] B. Sultana, F. Anwar, and M. Ashraf, "Effect of Extraction Solvent/Technique on the Antioxidant Activity of Selected Medicinal Plant Extracts," Molecules, vol. 14, no. 6, pp. 2167-2180, 2009.

[43] A. Pandey and S. Tripathi, "Concept of standardization, extraction and pre phytochemical screening strategies for 
herbal drug," Journal of Pharmacognosy and Phytochemistry, vol. 2, no. 5, pp. 115-119, 2014.

[44] J. H. Kim, M. J. Kim, J. M. Choi, S. H. Lee, and E. J. Cho, "Protective effects of Cirsium japonicum var. maackii against amyloid beta-induced neurotoxicity in C6 glial cells," Korean Journal of Agricultural Science, vol. 46, no. 2, pp. 369-379, 2019.

[45] M. Jang, K. H. Kim, and G. H. Kim, “Antioxidant capacity of thistle (Cirsium japonicum) in various drying methods and their protection effect on neuronal PC12 cells and caenorhabditis elegans," Antioxidants, vol. 9, no. 3, pp. 200-213, 2020.

[46] S. Nga, F. Tang, and B. K. Yee, "Chronic intracerebroventricular exposure to $\beta$-amyloid (1-40) impairs object recognition but does not affect spontaneous locomotor activity or sensorimotor gating in the rat," Experimental Brain Research, vol. 136, no. 1, pp. 93-100, 2001.

[47] N. Majlessi, S. Choopani, M. Kamalinejad, and Z. Azizi, “Amelioration of amyloid $\beta$-induced cognitive deficits by Zataria multiflora Boiss. essential oil in a rat model of Alzheimer's disease," CNS Neuroscience \& Therapeutics, vol. 18, no. 4, pp. 295-301, 2011.

[48] A. Ennaceur and J. Delacour, "A new one-trial test for neurobiological studies of memory in rats. 1: behavioral data," Behavioural Brain Research, vol. 31, no. 1, pp. 47-59, 1988.

[49] B. Grayson, M. Leger, C. Piercy, L. Adamson, M. Harte, and J. C. Neill, "Assessment of disease-related cognitive impairments using the novel object recognition (NOR) task in rodents," Behavioural Brain Research, vol. 285, no. 15, pp. 176-193, 2015.

[50] N. de Bruin and B. Pouzet, "Beneficial effects of galantamine on performance in the object recognition task in Swiss mice: deficits induced by scopolamine and by prolonging the retention interval," Pharmacology Biochemistry and Behavior, vol. 85, no. 1, pp. 253-260, 2006.

[51] J. Lockrow, H. Boger, H. Bimonte-Nelson, and A. C. Granholm, "Effects of long-term memantine on memory and neuropathology in Ts65Dn mice, a model for down syndrome," Behavioural Brain Research, vol. 221, no. 2, pp. 610-622, 2011.

[52] R. Lalonde, "The neurobiological basis of spontaneous alternation," Neuroscience and Biobehavioral Reviews, vol. 26, no. 1, pp. 91-104, 2002.

[53] J. Y. Choi, J. M. Lee, D. G. Lee et al., "The n-butanol fraction and rutin from Tartary buckwheat improve cognition and memory in an in vivo model of amyloid- $\beta$-induced Alzheimer's disease," Journal of Medicinal Food, vol. 18, no. 6, pp. 631-641, 2015.

[54] J. Y. Chan, H. L. Cheng, J. L. Chou et al., "Heat Shock Protein 60 or 70 Activates Nitric-oxide Synthase (NOS) I- and Inhibits NOS II-associated Signaling and Depresses the Mitochondrial Apoptotic Cascade during Brain Stem Death," Journal of Biological Chemistry, vol. 282, no. 7, pp. 4585-4600, 2007.

[55] M. Shariatpanahi, F. Khodagholi, G. Ashabi et al., "Ameliorating of memory impairment and apoptosis in amyloid $\beta$ injected rats via inhibition of nitric oxide synthase: possible participation of autophagy," Iranian Journal of Pharmaceutical Research, vol. 14, no. 3, pp. 811-824, 2015.

[56] A. Diaz, L. Mendieta, E. Zenteno, J. Guevara, and I. D. Limon, "The role of NOS in the impairment of spatial memory and damaged neurons in rats injected with amyloid beta 25-35 into the temporal cortex," Pharmacology Biochemistry and Behavior, vol. 98, no. 1, pp. 67-75, 2011.
[57] F. Torreilles, S. Salman-Tabcheh, M. Guérin, and J. Torreilles, "Neurodegenerative disorders: the role of peroxynitrite," Brain Research Reviews, vol. 30, no. 2, pp. 153-163, 1999.

[58] D. Puzzo, A. Palmeri, and O. Arancio, "Involvement of the nitric oxide pathway in synaptic dysfunction following amyloid elevation in Alzheimer's disease," Reviews in the Neurosciences, vol. 17, no. 5, pp. 497-523, 2006.

[59] A. Law, S. Gauthier, and R. Quirion, "Say NO to Alzheimer's disease: the putative links between nitric oxide and dementia of the Alzheimer's type," Brain Research Reviews, vol. 35, no. 1, pp. 73-96, 2001.

[60] J. Sun, X. Zhang, M. Broderick, and H. Fein, "Measurement of nitric oxide production in biological systems by using Griess reaction assay," Sensors, vol. 3, no. 8, pp. 276-284, 2003.

[61] D. Tsikas, "Analysis of nitrite and nitrate in biological fluids by assays based on the Griess reaction: appraisal of the Griess reaction in the L-arginine/nitric oxide area of research," Journal of Chromatography B, vol. 851, no. 1-2, pp. 51-70, 2007.

[62] S. Li, W. Wang, C. Wang, and Y. Y. Tang, "Possible involvement of NO/NOS signaling in hippocampal amyloid- $\beta$ production induced by transient focal cerebral ischemia in aged rats," Neuroscience Letters, vol. 470, no. 2, pp. 106-110, 2010.

[63] B. Sharma and P. M. Sharma, "Arsenic toxicity induced endothelial dysfunction and dementia: pharmacological interdiction by histone deacetylase and inducible nitric oxide synthase inhibitors," Toxicology and Applied Pharmacology, vol. 273, no. 1, pp. 180-188, 2013.

[64] T. T. Reed, "Lipid peroxidation and neurodegenerative disease," Free Radical Biology and Medicine, vol. 51, no. 7, pp. 1302-1319, 2011.

[65] D. A. Butterfield and C. M. Lauderback, "Lipid peroxidation and protein oxidation in Alzheimer's disease brain: potential causes and consequences involving amyloid $\beta$-peptide-associated free radical oxidative stress1, 2," Free Radical Biology and Medicine, vol. 32, no. 11, pp. 1050-1060, 2002.

[66] M. Shichiri, Y. Yoshida, N. Ishida et al., " $A$-Tocopherol suppresses lipid peroxidation and behavioral and cognitive impairments in the Ts65Dn mouse model of Down syndrome," Free Radical Biology \& Medicine, vol. 50, no. 12, pp. 1801-1811, 2011.

[67] G. P. Lim, F. Calon, T. Morihara et al., “A diet enriched with the omega-3 fatty acid docosahexaenoic acid reduces amyloid burden in an aged Alzheimer mouse model," Journal of Neuroscience, vol. 25, no. 12, pp. 3032-3040, 2005.

[68] I. ABIDIN, P. YARGIÇOGLU, A. AGAR et al., "The effect of chronic restraint stress on spatial learning and memory: relation to oxidant stress," International Journal of Neuroscience, vol. 114, no. 5, pp. 683-699, 2004.

[69] D. Del Rio, A. J. Stewart, and N. Pellegrini, “A review of recent studies on malondialdehyde as toxic molecule and biological marker of oxidative stress," Nutrition, Metabolism, and Cardiovascular Diseases, vol. 15, no. 4, pp. 316-328, 2005.

[70] A. M. Palmer and M. A. Burns, "Selective increase in lipid peroxidation in the inferior temporal cortex in Alzheimer's disease," Brain Research, vol. 645, no. 1-2, pp. 338-342, 1994. 